Muzikološki zbornik Musicological Annual XVII/2, Ljubliana 81

UDK 929 Mahler G.: 929 Krisper A.

Primoż Kuret.

GUSTAV MAHLER IN ANTON KRISPER

Ljubljana

I .

o prijateljstvu med Gustavom Mahlerjem in Ljubljancanom Antonom Krisperjem pišjo številni Mahlerjevi biografi. $1 \mathrm{~V}$ letih 1876 do 1878 sta bila študijska kolega na dunajskem

konservatoriju.2 0 tesnih zvezah med Mahlerjem in Krisperjem poroča tudi Dragotin Cvetko in se pri tem v veliki meri ski icuje na Josipa Mantuanija.3 Prav Josip Mantuani je namrec pri nas prvi omenil Antona Krisperja kot opernega skladatelja, ki je "studiral na Dunaju in bil sošolec slovitega Gustava Mahlerja. Uglasbil je opero, ki so jo, peli v Pragi najbrž leta 1885, ko je bil Mahler kapelnik tamošnjega nemškega deželnega gledališca. Ker je bil uspeh nepovoljen, je pustil Krisper skladanje. A o operi dosedaj ni bilo dognati nicesar, ne o snovi, ne o libretistu in njeni kakovosti. V bivšem nemškem giedališcu deželnem ni partiture in nikakega poročila $v$ aktih." 4 Mantuanijeve navedbe so ostali avtorji v glavnem ponavijali. dodajajo pa, da je Krisper kot student filozofije nemirno żivel in končno zapadel v neozdravljivo duševno bolezen.

Cvetko tudi popravija Mantuanija glede letnice Krisperjevega rojstva in jo postavija v leto 1859.5 Vendar se Cvetko tu moti. Mantuani navaja pravi podatek, to je 28. december $1858.6 \mathrm{Krisper}$ se je nato - po Cvetku - zaradi

1 Prim. vsaj: Berndt W. Wessling, Gustav Mahler, Prophet der neuen Musik. Hamburg 1974; Kurt Blaukopf, Gustav Mahler oder der Zeitgenosse der Zukunft. München, 1973.

2 Prim. Bericht über das Conservatorium für Musik und darstellende Kunst der Gesellschaft der Musikfreunde für Schuljahr 1876/77. Wien 1877. Pod zaporedno številko 316: "KRISPER Anton, aus Laibach, 18 . . - Comp. I, Cpt. I, Clv. I, Chg." (str. 18). Pac pa ni Krisperjevega imena med studenti, $k i$ jim je bila po prvem letu priznana prva klasifikacijska stopnja. Zato je vpisan v mubriki "Verzeichnis der Schüler, welche sich wegen Erkrankung den Prüfungen und Concursen nicht unterziehen konnten (str. 79): "KRISPER Anton, Clv. I, Nbfc. u. Cpt. Prim. se "Bericht ... für das Schuljahr 1877/78. Pod zaporedno stevilko 349: "KRISPER Anton, aus Laibach, $19 \mathrm{~J}$. - Comp. A II (Ausbildungsschule), Clv. I, Rep.G.d.M. (str. 19). Nato pa ga ni tudi med tistimi, ki zaradi bolezni niso delali izpitov. $V$ solskem letu $1878 / 79$ se Krisper na konservatorij ni ved vpisal.

3 Dragotin Cvetko, Zgodovina glasbene umetnosti na Slovenskem III, 
skladateljskin neuspehov usmeril v teoreticno delo. 0 tem teoretičnem delu z naslovom "Die Kunstmusik in ihrem Prinzipe, ihrer Entwicklung und ihrer Konsequenz", odn. "Die Musiksysteme in ihren Prinzipien" poroča tudi Hugo Riemann. 8 Po Riemannu je Krisper "dr. phil. v Gradcu", o razpravi sami pa sodi, da je "zelo zanimiva zgodovinsko-teoretična študija na harmonsko-dualistični osnovi".9 Krisper je svoje studije filozofije v Leipziqu uspešno končal kot tudi pozneje studij montanistike. Cvetko omenja nato Krisperja tudi v svoji razpravi o delu Gustava Mahlerja v ljubljanskem deželnem gledališču, kjer omenjene podatke (vkijučno z napačnim rojstnim datumom) povzema in zaokrožuje. 10

Pać pa niti Mantuani niti Cvetko ne omenjata zanimive korespondence med Mahlerjem in Krisperjem iz let 1879 in 1880. Mahlerjeva nisma so bila prvič objavljena že leta 1928 v reviji "Die Musik". 11 objavil jih je Hans Holländer z Dunaja s posebnim dovoljenjem Alme Marije Mahler, skladateljeve vdove. Tudi Hnlländer navaja vrsto podatkov o Krisperju, povzema że znane (da je bil skladatelj opere, izvedene $v$ Pragi, a neuspele) in noroča, da je sodil $v$ krog Mahlerjevih študijskih kolegov na dunajskem konservatoriju, med katerimi so bili se Hans Rott in Heinrich ter Rudolf Kryzanowsky. Poleg tega ne navaja nobenih novih podatkov o Krisperjevi operi. 12 sledi šest pisem, ki jih je pisal Gustav Mahler svojemu prijatelju Krisperju. To so pisma še ne dvajsetletnega mladeniča, "poetičnega, sanjskeaa in obsedenega z vizijami". 13 Zanimive so omembe skladateljskih načrtov (Rübezahl, nordijska simfonija), čeprav je većino teh del Mahler pozneje sam uničil.

Mahlerjeva pisma Antonu Krisperjs so nato izšla - čeprav v drugačnem, kronološkem zaporedju - še v ¿̌ěkem prevodu skupaj z drucoo Mahlerjevo korespondenco.14 Njihov slovenski prevod pa naj zaokrożi naše dosedanje znanje o zvezah Gustava Mahlerja z Ljubljano in Antonom Krisperjem.

Iz Mahlerjevega prijateljstva s Krisperjem je prav gotovo razumljiva domneva Dragotina Cvetka, da je "verjetno prav Krisper nagovoril Mahlerja, da se je odločil za Ljubljano, in mu s svojim vplivom nosredoval mesto kapelnika v Deželnem gledaližcu". 15 Mahler je bil kapelnik v Ljubljani v sezoni 1881-82 ter je stanoval na Mestnem trgu pri znani in ugledni trqovski družini svojega prijatelja Antona Krisperja. 16

Ljubliana 1960, str. 204, 205, 425.

4 Jnsip Mantuani, o slovenski operi. Zbori VI, 1930, str. 39.

5 Cvetko, 425.

6 Prim. "Krstno knjigo cerkve sv. Nikolaja 1835-1860 za leto 1858": roien 28. decembra 1858, ob 16,45, krščen 1. januaria 1859. Ime: Anton Josef Valentin. Naslov: Hauptplatz 264.

7 Cvetko, 205.

8 Hugo Riemann's Musiklexikon, 3. Auflage, Leipzig 1887, str. 525; 5. Auflage, str. 610 itd.

$9 \quad$ Ibid.

10 Dragotin Cvetko, Gustav Mahlers Saison 1881/82 in Laibach (Slovenien), v: Musik des Ostens 5,1969 , str. 74-83.

11 "Unbekannte Jugendbriefe Gustav Mahlers" von Hans Hollönder v: Die Musik. Monatsschrift herausgegeben von Bermhard Schuster, XX. Jahrgang - Heft 11, 
Vsi viri porocajo o Krisperju tudi kot o skladatelju. Nihče ne navaja natančnejših podatkov, le Dragotin Cvetko poroča o dveh njegovih klavirskih skladbah, "sonati" in "toccati"kot o "skladbah v. Lisztovem siogu, a s skromno invencijo". 17 Zlasti. zanimivi so bili podatki, ki govorijo o Krisperjevi operi in njeni izvedbi v Pragi. Vsi ti podatki so pomanjkljivi. Očitno je Šl $v$ njihovem raziskavanju najdlje Mantuani, saj pravi, da o "operi ni bilo dognati ničsar". I8 Usoda Krisperjeve opere ostaja tako še naprej uganka. Verjetno gre za opero z naslovom

"Zlatorog", kot izhaja iz pričevanja Krisperjevega nečaka z Dunaja, ki piše, da je bil Anton Krisper "izreden duh, ki je koncal svoje glasbene కtudije z doktoratom $v$ Leipzigu. Tam naj bi nastala tudi opera Zlatorog, ki obravnava neko staro kranjsko sago."19 Toda tudi ta domneva ni potrjena. Predvsem je gotovo, da $v$ času, ko je bil Mahler kapelnik nemškega gledališca v Pragi javno ni bila izvedena. V gledaliskem oddelku praškega Narodnega muzeja, kjer imajo shranjene plakate za vse predstave tega gledališa, ni najti plakata za Krisperjevo opero, niti krisperjevega imena. Ne omenja ga tudi ustrezna strokovna literatura.20

Anton Krisper se je s komponiranjem ukvarjal ozitno samo $v$ mladosti. studij glasbe ga je tudi povezal z Mahlerjem, in tako verjetno tudi Mahlerja z Ljubljano. Pozneje se je posvetil drugemu poklicu in tudi stiki $z$ mladostnim prijateljem niso već dokazani. Huda duševna bolezen ga je kmalu odtrgala od dela sploh. Umrl je star 55 let v bolnišnici za duševne bolezni Feldhof pri Gradcu 29. junija 1914. Pokopali so ga na ljubljanskem pokopališču sv. Krištofa 2. julija. Kot vzrok smrti je navedena "paranoia diabetes".21

August 1928. Stuttgart, str. 807-813.

Ibid., 807 .

Ibid.

G. Mahler, Dopisy - uredil František Bartoł, Státni hudebni vydavatelstvi. Praha 1962.

15 Cvetko, Zgodovina, 204.

16 Po podatku ing. Jožeta Krisperja iz Ljubljane.

17 Cvetko, Zgodovina, 204.

18 Mantuani, 39.

19 Privatno pismo dipl. ing. Josepha Krisperja z dne 2.9. 10. 1979 in 26. 11. 1980 z Dunaja.

20 Pregledal sem glasbeni arhiv praškega Narodnega gledališča, gledališki oddelek Narodnega muzeja, dalje Muzej ðeške glasbe in glasbeni oddelek drzavne biblioteke Karlove univerze v Pragi. Prim. še: Oskar Teuber, Geschichte des Prager Theaters 1817-1887. I - III. Prag 1888; "50 Jahre Neues Deutschen Theater Prag 1888-1938." Beiträge zum Jubiläum Prag 1938; Deutsches Königl. Landestheater in Prag - Almanach und Adressbuch zum Jahre 1881. Prag 1881; Theater-ALmanach des deutschen Landestheaters $1881,1887,1890$ etc.

21 Prim. "Mrliško knjigo stolne župnije ljubljanske 1871-1925" za leto 1914: zaporeina številka 17 je prečrtana. Umrl: 29. junija 1914 ob 12 opoldne. Poknpan: 2. julija ob 16h. Stanoval: Feldhof bei Graz. Hisna stevilka: Irrenanstalt. Ime, priimek, stan: Dr. Anton Krisper, ledigen Bergingenieur. Starost: $55 \mathrm{l}$, rojen $28 / 12$ 58. Bolezen ali varok smrti: paranoia diabetes. Previden ali ne: ?. Pokopališe: St. Cristoph. 
II.

PISMA GIISTAVA MAHLERJA ANTONU KRISPERJU I7. LET 1879 in 1880

Dunaj, Café Imperial

(poštni žig: Dunaj, 22. 9. 1879.)

Moj ljubi Anton!

Pravkar sem prišel na Dunaj in poiskal kraje, kjer sva skupaj

tolikokrat delila radost in trpljenje. Jaz sem najnesrečnejši srečnik, ki se je kdaikoli ranil med vrtnicami. Zdaj stoji novo ime $v$ mojem srcu poleg Trojega, sicer le క̌epetaje in zardevajnče, toda nič manj silno. - Kdaj prideš na Dunaj? Piši takoj. Selim se zdaj v neko znano stanovanje. Ah, rad hi bil blizu starim dobrim časom. Sem pač pravi norec. Naj bo! Otroci so bol,jši kot starci. Preveč sem nemiren, da bi lahko več pisal. Moji starši te prisrčno pozdravljajo kakor tudi Tvoj

zvesti Gustav Mahler

Dunaj, III. Rennweg 3.

Parterre, vrata $10 \mathrm{~B}$.

Moj ljubi Anton!

Tregam, da Te to pismo ne dobi, in ga pošiljam na Troj stari naslov. Tudi se ne čudi, Če bo nekaj krajše - vedno se mi zdi, da ga pǐ̌em vendar le tja v tri dni. Kaj pa je, da ne daš nobenega znamenja živijenja od sebe, tako da nimam niti pojma, kje naj Te najdem?

Za moj curriculum vitae teh 2 mesecev bo dovolj nekaj besed:

Bil sem

$+++$

Po polurnem odmoru spet začenjam, ker mi je ta zlomkova sobarica pozabila naliti svetilko in sem moral tekati okoli vseh trgovcev s petrolejem našega okraja, dokler mi ni neka dobra duša odprla svoje prodajalne, kajti ura je že $1 / 211$. -

No, da se spet povrnem $k$ svojemu curriculu vitae. Ljubi prijatelj, kar zelo sem se zapletel v sladke verige ljubljenca bogov - junak zdaj "zdihuje, vije roke, ježi in moleduje" etc. etc. Resnično sem čas porabil v glavnem za to, da sem se zaril na najrazličnejše načine v sladke bolečine, vstal sem $z$ "ah" in $z$ "o" sem క̌el spat; živel sem $v$ sanjah in buden sanjal in tako sta nretekla 2 meseca in božič je spet tu - naj mi prinese res nekaj lepega. Cez teden dni sem $v$ Jihlavi in se hom iz svojih rožnatih sanj prebudil $v$ še bolj rožnate dneve.

Tudi nova senca lebdi zdaj v ozadju mojih sanjskih slik, vendar moram najprej počakati njihovega nosilca. Ko se pokaže, Ti bom o njem kaj več novedal - domnevam le, da je nekakక̌en prastari nordijski kralj, ki me hoče s svojimi junaki in gostijami pregnati iz mojeca miru. Tudi sem srknil nekaj hipokrene - cesar je srce polno, o tem usta govore.

Zdaj dovolj osovraženega smehljaja - prisilil sem se, da si prisvojim vedrejşi pastoralni slog, da ne zapadem v stari obrabljeni lamento. Nočem. vzdihovati, pa se tudi ne smejati. $V$ moji corf je nekaj eskadronov kletvic in preklinjanja; naj zdaj odkorakajo. "Naj hudič vzame ves ta capinski svet!" Moje oči so kot izsušene citrone - tudi ene kapljice ni več $v$ njih. Bolesti tega sveta naj vse poskusim in niti ena naj mi ne ostane prihranjena. To se Ti bo zdelo zagonetno, - bojim se, da bom kmalu lahko dal strašno pojasnilo. Dotlej se dobro imej in kmalu piši. Zdaj grem spat, kajti treba mi je miru.

Lahko noz, ljubi Anton! Lahko nož!

Troi zvesti

Gustav Mahler 
Dunaj, Cottageverein, Karl Ludwigstrasse st. 24 težav.

¿e moreš, mi posodi pet cekinov, toda samo, ce gre brez vsakršnih

Dunaj, 14. decembra. To pismo nosim že dva tedna pri sebi .v žepu. Odgovori takoj! $V$ petek se odpeljem domov.

\section{Ljubi Anton!}

(brez datuma, Dunaj, zač. 1880)

Sprejmi prijazno moje nekoliko zapoznelo vošcilo k novemu letu. To bodi tudi prva beseda po dolgem molku. Tvoje pismo sem prejel svojčs v Jihlavi in ne bo Ti nezanimivo zvedeti, da sem tam dirigiral predstavo, kjer je kot prva pevka pela neka gospodična Hassmann, ki je sicer najbolj plosko bitje med ženskami, kar sem jih kdaj videl. Sicer pa nisem bil dolgo tam, marveč sem začel na Dunaju veselo popotniško živijenje, se pravi, da sem se vsakih 14 dni preselil v novo stanovanje, ne glede na različne hotele, in imam že 5. stanovanje. Da moje delo ni preveč uspešno potekalo, si lahko predstavljaš; zdaj, ko bi bil $v$ najboljšem razpoloženju me moti spet jok majhnega otroka - in tako padam iz ene jeze $v$ drugo. K1 jub temu vendar unam, da bom skončal 1. dejanje Repošteva (Rübezah1). Sicer pa je pesem, odkar si jo Ti videl, dobila povsem novo podobo. Marsikaj na njej res ni slabo. Kdaj misliš priti spet enkrat na Dunaj? In kaj sploh počenjas? Si delal in se dobro počutis? Prosim Te, ukroti že svoj metafizični ogenj in mi odgovori preprosto in zvesto na ta prozaična vprašanja.

Sam bi bil najboljక̌e volje, ko bi me ta nesrečni otrok ne motil pri najbolj ̌̌em delu.

Bodi najlep̌še pozdravljen in mi kmalu piši! Moj naslov je:

Gustav Mahler

I. Wippl ingerstrasse st. 12

II. stopnišce, 4. nadstropje desno

Moj 1 jubi Anton!

(Poštni žig: Dunaj, 18. 2. 1880)

Zdaj sedim pozno ponoči $v$ svojem novem stanovanju. Pred menoj leži nekaj knjig in čibuk se kadi. Vendar mi kajenje kar ne diši in sem tudi preveč raztresen, da bi lahko karkoli bral. Moje misli se vedno vračajo $k$ Tebi. In pri tem si mislim, da je bolje pustiti knjige v miru in biti skupaj s Teboj. Ce bi Ti bil pisal pred pol ure, bi bili spet tekli na papir stari vzdihljaji in solze. Zdaj pa sem mnogo mirnejši. Knjiga je prava leydenska steklenica bolečine, ki prestreza ves tok občutij in $\mathbf{j i h}$ zbere $v$ sebi - sem in tja se baterija res sproži, ¿e ji prideš preblizu, in pošlje spet v svetlih iskrah vse nazaj $k$ povzročitelju. - To je res prva ura po dolgem času, da najdem tako mirne besede. Te pa sem prihranil tudi za Tebe, da bos vendar videl, kako sem pos?ušen in kako rad izpolnim Troje želje.

$\checkmark$ sobi poleg stanuje devica, $k i$ ves dan sloni na svojem spinetu. Vsekakor ne ve, da bom moral že zaradi tega spet kakor Ahasver zagrabiti svojo popotno palico. Nebo ve, ali se bom kdaj kje naselil. Vedno me odpiha nekakšen nemogoč sostanovalec iz moje izbe $v$ neko drugo. Moja sedanja je: VI., Windmühlaasse st. 39, I. nadstropje, vrata 18.

Piši že vendar kaj več o sebi. Kdaj pa prideš na Dunaj? Saj je bilo vendar dogovorjeno, da boš preżivel 2. semester tu? Pridi vendar konžno, saj vendar nisi zavezan, da boš večno kljuval v tem pristaniškem mestu. Tam nǐcesar ne zamudiš in tu nisi nič na škodi. Piši kmalu!

Prisrčne pozdrave od Trojega 
(Poštni żig: Dunaj, 3. 3. 1880.)

Moj ljubi prijatelij!

Zakaj vendar molčiš? Ali mojih pisem nisi dobil? Moje żivljenje poteka $v$ starem običajnem diru. Cez noč je prišla pomlad in z njo staro hrepenenje in otožnost. Pravkar sem napisal nekaj verzov, $k i$ Ti jih pošiljam, ker $\mathrm{Ti}$ bodo lahko najbolje razkrili mojo notranjost.

\author{
VERGESSENE LIEBE \\ Wie öd' mein Herz! Wie leer das All'! \\ Wie gross mein Sehnen! \\ 0 , wie die Fernen Tal zu Tal \\ sich end los dehnen! \\ Mein süsses Lieb! Zum letzten Ma1!? \\ Ach, muss ja ewig diese Qual \\ in meinem Herzen brennen! \\ Wie strahlt' es einst so treu und klar \\ in ihren Blicken! \\ Das Wandern liess ich ganz und gar \\ trotz Winters Tücken! \\ Und als der Lenz vergangen war, \\ Da tat mein Lieb ihr blondes Haar \\ wohl mit der Myrthe schmücken! \\ Mein Wanderstab! Noch einmal heut \\ komm aus der Ecken! \\ Schliefst du auch lang! Nun sei bereit! \\ Ich will dich wecken! \\ Ich trug es lang mein Liebesleid \\ Und ist die Erde doch so weit - \\ So komm, mein treuer Stecken! \\ Wie lieblich lächelt Berg und Tal \\ in Blütenwogen! \\ Kam ja mit seinem süssen Schall \\ der Lenz gezogen! \\ Und Blumen blühn ja überall - \\ die haben nicht gelogen!
}

Predvsem pa Ti sporočam načrt za poletno potovanje, ki nanj mislimo $s$ Heinrichom in Rudolfom Kryzanowskim $v$ juliju in pri cemer zagotovo računamo, da prideš z nami.

Peš skozi Ceški gozd (edini pragozd v Evropi in čisto tuji in edinstveni ljudje s čudovitimi żenskami), nato prav tako skozi

Fichtelgebirge. Eqer - Beireuth - Nürnbero - in nazadnje $v$ Oberammergau $k$ pasijonskim igram - $v$ treh tednih smo naokrog in gremo nato naravnost (če je mogoč boš ostal nekaj dni pri meni v Jihlavi) domov. Ali Ti ta predlog ne ugaja? Bilo bi vendar prav prijetno in sploh smo se o tem dogovorili že prejšnje poletje. Prosim Te, odgovori takoj

Trojemu vedno

zvestemu

Gustavu Mahlerju

Ljubi Anton!

(Poštni žig: Dunaj, 14. 3. 1880.)

Zelo sem zaskrbljen, ker še vedno nimam nobenega odgovora od Tebe. 
Kje pa si? in kaj sploh počneš? Ali naj tega jaz, ki sem morda poleg Trojih staršev edini na svetu, ki skrbi zate, ne bi smel vedeti? Ali si bolan? Ah, ljubi Anton, jaz sem, - strašno hrepenim po tem, da bi Te videl in bi bila skupaj.

Tako sem sam!

$\mathrm{Ne}$ vem, če bom to lahko క̌e dolgo prenašal. Zdi se mi, kot da se bom vsak trenutek zrušil!

Zdaj sem bojeval hud boj - in ga še vedno nisem končal. Tega Ti ne morem pojasniti -

Prvič me je ta svet zares zgrabil v żivo in zbledeli skupni kraji, ohrabljene ženske zgodbe, $k i$ sem jih poslušal vedno le s sočutnim nasmehom, so me zdaj zajeli v svoj ples kakor rusalke in zdaj mi udarjajo valovi čez glavo.

Prosim Te, piši takoj, če naj ne verjamem, da si name hud. Objema Te Troj zvesti

Moj naslov:

$$
\text { Gustav }
$$

G.M. Dunaj

Windmühlgasse, št. 39 , I. nadstropje, vrata 18

\section{SUMMARY}

When studying at the Conservatorium in Vienna Gustav Mahler became friends with Anton Krisper, of Liubljana. Krisper (1858-1914) is generally taken to have been a highly gifted and extremely sensitive oharacter. In 1879 and 1880 Mahler wrote six letters to Krisper, at that time not yet twenty years old. These letters are important because they contain Mahler's communication concerning his work and plans (Rübezahl, a fairy-tale play; a Nordische Symphonie; both of them later destroyed) and reveal his impassioned disposition, filzed with poetry. Later on Anton Krisper went to Leipzig to study there philosophy and then mining engineering. He is often quoted in connection with an opera (probably ziatorog) that possible had its first premiere in Prague - but evidence for this is lacking. Later on he wrote a treatise entitled "Die Kunstmusik in ihrem Prinzip, ihrer Entwick.lung und ihrer Konsequenz bzw. Die Musiksysteme in ihren Prinzipien". In his Musiklexicon Hugo Riemann characterises it as "a very interesting historical-theoretical study on harmonic-dualistic basis". In all likelihood it was Krisper who persuaded Mahler to decide and come to Ljubljana. Here he was in the 1881-82 season the conductor at the Ljubljana theatre. Since that time no more relations between the two friends can be traced. Krisper died in a mental hospital at Feldhof near Graz in 1914 and was burried in Ljubljana. 